\title{
Reaction to the paper Tempest in a Teapot: The exaggerated problem of transport-related residential self-selection as a source of error in empirical studies
}

\author{
Bert van Wee ${ }^{a}$ \\ Delft University of Technology
}

\author{
Marlon G. Boarnet ${ }^{\text {b }}$ \\ University of Southern California
}

\section{$1 \quad$ Introduction}

Petter Naess in his slightly provocative paper states that "the existence of transport-attitude-based residential self-selection hardly represents any threat to the validity of the basic knowledge on how residential location within urban contexts influences travel behavior." The paper is a very interesting and inspiring contribution to the debate on the causal relations between the built environment, travel behavior, residential choice, and attitudes. We value the contribution to the debate, regardless of the extent to which we (dis)agree. Scientific debates are very valuable and contribute to our understanding.

In this paper we exclude residential self-selection (RSS) based on socio-economic-demographic variables because there seems to be consensus that this RSS is important and should be included in research and planning. So the discussion is on attitudes-based RSS.

In section 2 we will respond to the points of his line of reasoning. Section 3 adds some thoughts on the debate. Before doing this we first elaborate a bit more on the topic of land use- travel behavior and residential self-selection in general.

Theory suggests a link between land use and travel, and a large body of studies, going back decades, suggests the direction of that relationship. If nothing else, trip distances would be shorter where origins and destinations are closer together. (Crane 1996 notes reasons why the resulting impact on travel mode and trip generation and hence VMT would be ambiguous.) Additionally, recent evidence, controlling for residential selection a number of ways, has shown an association between land use and travel behavior. Some of those techniques control for demographic-based residential selection (e.g., the instrumental variable approaches in Bhat and Guo 2007 or Brownstone and Golob 2009) but others, particularly studies based on natural experiments or movers, likely also control for attitudinal-based residential selection (e.g., Boarnet et al. 2005; Handy et al. 2006; Krizek 2003) The evidence, much broader than these studies, led the U.S. National Research Council's 2009 report on "Driving and the Built Environment" (NRC 2009) to conclude that the preponderance of the evidence suggests a causal link.

Residential self-selection is still an important issue, and here we suggest two ideas. General directions of the magnitude of impact can be inferred and one of us (Boarnet) has co-authored work suggesting ranges of impacts, advising the California Air Resources Board that such impacts can and should be used to assess compliance with greenhouse gas emission reduction targets. ${ }^{1}$ So nihilist statements that we know nothing due to residential self-selection are unfounded. Yet such statements do not so much appear in the scientific literature on this topic as in the popular commentary on that literature. Naess's article is an important reminder that we know much, but we insist that basic scientific inquiry requires additional studies. Importantly, a good amount of what we know about land use and

\footnotetext{
${ }^{a}$ g.p.vanwee@tudelft.nl

b boarnet@usc.edu

Copyright 2014 Bert van Wee and Marlon G. Boarnet

Licensed under the Creative Commons Attribution - NonCommercial License 3.0.
} 
travel comes from studies that correct for residential self-selection (e.g., see Salon et al. 2013), and we would not be as confident about the direction and magnitude of effects as we are were it not for the many years of study into the residential selection question that preceded our current moment. We agree with Naess's claim that residential selection is not the only scientific question in this literature (see, e.g., Boarnet 2011), and we believe other questions - about context sensitivity, land use planning, and before-after experimental-control group evaluation, are also vital. Yet additional inquiry into attitudes, moving patterns, and selection is still an important topic.

\section{A reaction on the statements of Petter Naess}

This section is structured along the line of reasoning of Petter Naess.

a) The causal mechanisms by which residential location influences travel behavior are well-understood theoretically and empirically well-documented

We more or less agree, but some important questions remain, including:

1. The research so far is still predominantly based on cross-section data. Only after several panel based data models are estimated we have a clear picture on magnitude of causal mechanisms.

2. Researchers have developed quite complex causal models for links between the built environment, travel behavior, residential choice, and attitudes, but so far we do not have the (preferably: panel) data to estimate those models.

3. Most of the research originates from the USA. We need more studies from other regions, such as the EU. The public transport system and cycling/walking differ strongly between, for example, the USA on the one hand, and several European countries or Japan, on the other hand. Consequently we expect the importance of attitudes related RSS on the impact of the built environment on travel behavior to differ. And we should study developing countries for the same reason. For those countries the topic might be even more important because of the rapid growth in the population and economy, and consequently the huge changes in the built environment and travel behavior. In these countries the options to influence travel behavior, travel satisfaction and match the built environment with residential preferences are relatively large.

4. Research has often not addressed the (potential) importance of immigration of specific ethnic groups with their own preferences and behavior with respect to activities and travel, an exception being Chatman and Klein (2009). The importance of this topic might strongly vary between study areas due to the fact that immigrants are generally not equally distributed over residential areas, but do self-select them in specific areas (Bhat et al., forthcoming) ${ }^{2}$.

\section{b) Transport-related residential self-selection is in itself a demonstration of the influence of} residential location on travel behavior

We agree. Even if the full effect of the built environment on travel behavior would result from RSS, it still is relevant to build residential areas that match the wants and needs of people who prefer to

\footnotetext{
${ }^{1}$ See http://arb.ca.gov/cc/sb375/policies/policies.htm.

${ }^{2}$ We thank Chandra Bhat for suggesting this topic, in an e-mail discussion.
} 
travel by car, or those of people who prefer to walk or cycle, especially if there is a shortage of such areas (see also section 3).

In addition we argue that the demonstration of Built Environment (BE) impacts on travel does not mean changes in $\mathrm{BE}$ will bring about equally large changes in travel. A very important question is if there is an undersupply of specific residential areas. We discuss the importance of whether we have an undersupply of this kind of development, and the difference between building new residential areas versus changing existing residential areas in section 3.

c) Exact, context-independent quantification of effects of residential location is neither possible nor necessary for reasonable land use policy-making

We split this statement into "possible "versus "necessary," starting with "possible." Of course, exact quantification resulting in coefficients that are applicable in other contexts ("generalizations") is never possible - the explanatory power of models for complex human behavior is limited. We agree with Petter Naess on this point. But the suggestion that it would not be possible to develop quantitative estimates of effects is - to our opinion - too strong. The recent article by Salon et al., (2013) summarizes evidence on effect sizes from current data. We think if enough high quality research as referred to under point a) would be carried out, the magnitude or a range of magnitudes of quantitative effects can in the future be better addressed than currently is the case.

Is it necessary to have context-independent quantification for land use policy? We think it is at least important to have insights into quantitative effects of built environment features on travel behavior. Policy makers need to have insights into all the major pros and cons of alternatives for planning concepts. These include travel behavior related impacts and others. Especially if planning concepts that reduce motorized travel have major cons, such as higher costs, quantitative insights, preferably even expressed in monetary terms, into the pros and cons of these concepts are needed to understand how costs and benefits balance. This is particularly true if ex ante evaluations are based on Cost-Benefit Analysis (CBA). And even if a Multi Criteria Analysis (MCA) would be used, insights into quantitative effects are relevant-policymakers need some quantification to trade-offs.

Even though CBA quantifies effects, these are not exact numbers. But is this a problem? For policy reasons exact quantification - if it is possible at all —is often not needed. What is important is the question of whether policy makers would come to other decisions if they were "perfectly" informed. In many cases uncertainties do not lead to other rankings of projects (Borjesson et al. 2012). In addition, even if exact quantifications of residential effects would be possible, several other important uncertainties remain, such as estimates of the costs of policies, or the valuation of several effects. However, more advanced methods and "better" datasets do not per definition only marginally change coefficients (or give additional error term related insights.) In some cases the coefficients can change substantially, as well as significance levels. In extreme cases signs of coefficients can even change, but we do not expect this to be the case for key land-use variables, such as densities or levels of mixed use.

\section{d) Travel attitudes are not necessarily antecedent to choices of residential location but may themselves be influenced by residential location}

We agree. As shown by several authors that Naess refers to in his paper it is very likely that attitudes will be influenced by experience with respect to residential choice and travel behavior on attitudes. However, we think it is very unlikely that these attitudes are only explained by the "reversed causality." We argue that the magnitude of the impact of experience with respect to residential choice and travel behavior on attitudes (the "reversed causality") is still unknown. We believe that more research into the question of attitudes, and whether they are time invariant or vary based on life experience and environmental exposure, is important (e.g., see Boarnet 2011). 


\title{
e) People may have preferences for particular modes, but does anyone prefer to drive long distances rather than short?
}

There are indications that people do not always prefer to minimize travel distance, at least for commuting: people prefer to travel some 15-20 minutes (see, for example, Mokhtarian and Salomon 2001, who found an "ideal" commute time of just over 16 minutes). If the statement is only meant to be applicable for trips that take longer, we agree with Naess: most people do not prefer to travel longer distances over shorter. He might be right that the ideal travel time being substantially longer than zero could be particularly applicable to commuting, not to other trip purposes. But this in itself is only limitedly relevant. People might still chose to travel over longer distances, despite the disutility of travel, because of the valuation of the activity (compared to the valuation of a nearer activity). For example, people may prefer a job at 45 minutes over the second best job at a distance of maximum 15 minutes. In other words, "accessibility benefits" may more than compensate for the disutility of longer travel times. So, the key point is not the question if people prefer to travel over shorter distance, but which preferences for travel, activities, and neighborhoods they have, how they trade-off those preferences, which choices they make, and how they value the outcomes.

This does not mean planning concepts that allow for shorter trip distances are not relevant; they certainly are. And even if the potential (theoretically possible) impact of land use on travel behavior due to compact building and mixed use does not occur in practice, there must be accessibility benefits

for travelers, that they value at least as highly as the benefits of the potential decreases in Generalized Transport Costs (Van Wee 2011).

\section{f) Activity preferences may be just as important as travel preferences in attitude-based residential self-selection}

We agree.

\begin{abstract}
g) Travel attitudes are not the most important criteria of residential preferences, and several constraints can prevent people from realizing what they would otherwise prefer.
\end{abstract}

We agree.

\section{Additional thoughts on the debate}

Next we add some thoughts on the debate.

a) Research into the relationships between the built environment, RSS, and travel behavior is not only carried out to support planning of residential areas.

Other reasons could be decisions on new infrastructure, e.g., a new light or heavy rail line in existing urban areas (see also point 2), or just scientific curiosity (see Cao and Schoner, forthcoming.

b) The possibly reduced effect of the built environment on travel behavior due to RSS is less relevant for residential areas that still need to be built, compared to current areas that might be redesigned. In the longer term the distinction between "new areas" versus "redesigned areas" will diminish.

If residential choice of households is influenced by travel related attitudes, people that prefer to 
travel by public transport, or to cycle or walk, or be more likely to live in neighborhoods that allow them to travel this way. People without such preferences will be overrepresented in low density car oriented neighborhoods. If in the latter neighborhoods a light or heavy rail line will be built, forecasts of travel behavior ignoring RSS will overestimate the use of that line: the people living near the stations / stops will have lower than average preferences to travel by rail.

In the long run, say several decades, the overestimation will be reduced due to households moving and "demography."

c) The importance of attitudes based RSS for the impact of the built environment on land use depends on the ratio of supply and demand for different types of neighborhoods, the ratio of households with a preferences for such neighborhoods versus all households, and the level of mismatch between both.

An important question is if and to what extent there is a shortage of neighborhoods attractive for those households that prefer to travel by other modes than the car. The larger the shortage, the higher the benefits of building new residential areas that meet the preferences of those households.

The more households are able to self-select in neighborhoods they prefer based on their travel related attitudes, the larger the impact of ignoring RSS in studies into the impact of the built environment on travel behavior. On the other hand it is important to notice that if people move to a neighborhood that matches their travel related attitudes, these attitudes do not necessarily have to influence residential choice-maybe people chose for the neighborhood for other reasons. See for a discussion on this topic (and several others related to RSS) Cao and Chatman (submitted).

d) High-density mixed-use areas with good facilities for cycling, walking and public transport facilities are more robust.

Petter Naess touches upon the fact that in the future oil prices might increase, for example due to climate change policies. Such increases might also result from the depletion of oil or from geopolitical instability. In such futures the multi-modal neighborhoods can allow people to reach activity locations with less oil, because more opportunities are available at shorter travel distances and because of the availability of travel options other than driving. In general, we believe such multi-modality will be desirable in the face of possibly (and likely) increasing fossil fuel costs, but we note that persons could reasonably conjecture that a broad range of technological advances could allow similar adaptations without a land use response. Having said that, we note that in the U.S. and Europe there is much evidence that segments of urban populations prefer multi-modal neighborhoods, based on the increased popularity of walking and cycling in large cities in those countries (e.g., Boarnet 2013).

e) The importance of attitudes related RSS probably depends on the measurement of attitudes

We think that which attitudes matter for RSS and its importance for the land use and travel behavior debate depends on which attitudes are measured and how. We argue the role of attitudes is not fully understood yet. It is very well possible that if some researchers find only a limited (or even no) role of attitudes this can to some extent be explained by which attitudes are measured and how.

\section{Acknowledgement}

We thank Jason Cao (guest editor of this special issue) for his comments on the draft version of this paper. 


\section{References}

Bhat, C. R., and J. Y. Guo. 2007. A comprehensive analysis of built environment characteristics on household residential choice and auto wwnership levels. Transportation Research Part B 41(5): 50626.

Bhat, C. R., R. Paleti, R. M. Pendyala, K. Lorenzini, and K. C. Konduri, forthcoming. Accommodating immigration status and self selection effects in a joint model of household auto ownership and residential location choice. Transportation Research Record.

Boarnet, M. G., C. Anderson, K. Day, T. McMillan and M. Alfonzo. 2005. Evaluation of the California Safe Routes to School legislation: Urban form changes and children's active transportation to school. American Journal of Preventive Medicine 28(2; Suppl.): 134-40.

Boarnet, M. 2011. Longer view: A broader context for land use and travel behavior, and a research agenda. Journal of the American Planning Association 77(3): 197-213.

Boarnet, M. 2013. The declining role of the automobile and the re-emergence of place in urban transportation: The past will be prologue. Regional Science Policy and Practice 5(2): 237-253. doi: $10.1111 /$ rsp3.12007.

Börjesson, M., J. Eliasson and M. Lundberg. 2012. Is CBA ranking of transport investments robust? Transport Economics and Policy 48(2): 189-204.

Brownstone, D., and T. Golob. 2009. The impact of residential density on vehicle usage and energy consumption. Journal of Urban Economics 65(1): 91-98.

Cao, X., and D. G. Chatman. Submitted for review. How will land use policies affect travel? A theoretical perspective on the importance of residential sorting.

Cao, X., and J. Schoner, forthcoming. The influence of light rail transit on transit uses: An exploration of station area residents along the Hiawatha line in Minneapolis. Transportation Research Part A.

Chatman, D.G., and N. Klein. 2009. Immigrants and travel demand in the United States: Implications for transportation policy and future research. Public Works Management and Policy 13(4): 312-327.

Crane, R., 1996. On form versus function: Will the New Urbanism reduce traffic, or increase it? Journal of Planning Education and Research 15(2): 117-26.

Handy, S., X. Cao, and P. Mokhtarian. 2006. Self-selection in the relationship between the built environment and walking: Empirical evidence from northern California. Journal of the American Planning Association 72(1): 55-74.

Krizek, K. J. 2003. Residential relocation and changes in urban travel: Does neighborhood scale urban form matter? Journal of the American Planning Association 69(3): 265-81.

Mokhtarian, P. L., and I. Salomon. 2001. How derived is the demand for travel? Some conceptual and measurement considerations. Transportation Research Part A 35(8): 695-719.

National Research Council (NRC). 2009. Driving and the Built Environment: The Effects of Compact Development on Motorized Travel, Energy Use, and $\mathrm{CO}^{2}$ Emissions. Committee on Relationships Among Development Patterns, Vehicle Miles Traveled, and Energy Consumption. Washington, DC: National Academies Press.

Salon, D., M. Boarnet, S. Handy, S. Spears, and G. T. 2013. How do local actions affect VMT? A critical review of the empirical evidence. Transportation Research Part D 17(7): 495-508.

Van Wee, B. 2011. Evaluating the impact of land use on travel behaviour: the environment versus accessibility. Journal of Transport Geography 19(6): 1530-1533. 